\title{
Evaluation of an ELISA system for determination of class-specific antibodies to native and denatured DNA in man
}

\author{
G M HALLIDAY, ${ }^{1} \mathrm{M}$ R SALAMAN ${ }^{1} M$ H SEIFERT ${ }^{2} \mathrm{~K}$ J JOHNSON ${ }^{3}$ AND \\ A D B MALCOLM \\ From the Departments of ${ }^{1}$ Immunology and ${ }^{3}$ Biochemistry, St Mary's Hospital Medical School, and the \\ ${ }^{2}$ Department of Rheumatology, St Mary's Hospital, London W2
}

SUMmARY Enzyme-linked immunosorbent assays (ELISA) have been set up for determination of plasma IgG and IgM antibodies to native (n) and denatured (d) DNA. Normal male and female donors generally gave low values in the assays for IgG; IgM control values were higher, particularly in females. Mean values for patients with systemic lupus erythematosus (SLE) were greatly raised in all four categories of assay in relation to the control (female) group. Levels of IgG anti-nDNA in SLE correlated well with a standard diagnostic test (Farr), and this ELISA assay was more successful than Farr in discriminating between patients and normal females. No such correlation with Farr was found for IgM anti-nDNA. Correlations were found in SLE between levels of antibodies to nDNA and dDNA. Inhibition tests-including those with a plasmid DNA preparation containing no single-stranded regions-showed that most of the IgG antibodies determined in the 'native' assay were able to bind to nDNA and dDNA with comparable avidity, whereas most of those reacting in the 'denatured' assay could only bind dDNA. The former antibodies were probably directed against shared determinants on the deoxyribose-phosphate backbone and the latter against base-dependent structures not exposed in nDNA. Inhibition results for IgM assays were similar, though the predominance of antibodies specific for dDNA appeared less marked. ELISA assays could well prove more useful than established methods in diagnosis and monitoring of SLE and other diseases.

Key words: DNA antibodies, systemic lupus erythematosus.

Many different procedures have been used for the assay of antibodies to DNA in systemic lupus erythematosus (SLE) and other autoimmune disorders. Among the best established are the Farr assay in which complexes formed between antibody and radioactive DNA are precipitated at high salt concentration, ${ }^{1}$ the filter radioimmunoassay in which complexes are collected on cellulose ester discs, ${ }^{2}$ and the immunofluorescent technique employing the kinetoplast DNA of Crithidia luciliae. ${ }^{3}$

Such methods have been of great value in the diagnosis of SLE, ${ }^{4}$ yet none combine the character-

Accepted for publication 5 March 1985.

Correspondence to Dr M R Salaman, Department of Immunology, St Mary's Hospital Medical School, London W2 1PG. istics that would be required of an ideal system. Thus the assay should provide a quantitative measure of antibody and show high sensitivity and reproducibility. It should be available in two forms, for antibodies to native (nDNA) and denatured DNA (dDNA). ${ }^{5}$ It should carry a built-in check that the DNA ligand being assayed is in fact immunoglobulin, together with the related capacity to discriminate between antibody classes. ${ }^{3}$ Finally, it should be simple to perform, lending itself to the determination of multiple samples.

Solid-phase immunoassays are in principle able to provide these advantages, and we therefore present our experience with an enzyme-linked immunosorbent assay (ELISA) for antibodies to DNA. 


\section{Patients and methods}

PATIENTS AND CONTROLS

Blood was collected from 13 female patients fulfilling the revised American Rheumatism Association criteria for SLE. ${ }^{6}$ At the time of the study five of the patients were regarded as clinically active and were being treated with prednisolone (5-20 mg/day) with, in three instances, azathioprine (150 mg). Other patients were in receipt of non-steroidal antiinflammatory agents.

Normal females (nine) and males (eight) were members of staff at St Mary's Hospital Medical School.

Blood was taken into heparin $(10 \mathrm{IU} / \mathrm{ml}$ of blood), and the separated plasma was stored at $-20^{\circ} \mathrm{C}$.

ENZYME-LINKED IMMUNOSORBENT ASSAY (ELISA) FOR ANTIBODIES TO DNA

ELISA assays were developed for determining antibodies to native and denatured DNA. The assays were carried out in flat-bottom microtitre plates (M29AR, Sterilin) and, unless otherwise stated, additions to the wells were in $60 \mu$ l volumes, incubations were for $1 \mathrm{~h}$ in a $37^{\circ} \mathrm{C}$ water bath, and washing between each assay step was with phosphate-buffered saline (PBS) containing 0.05\% (v/v) Tween 20 (Sigma).

DNA preparations for coating the wells were obtained as follows. Native DNA (nDNA) from calf thymus (D1501, Sigma) was dissolved at $1 \mathrm{~g} / \mathrm{l}$ in citrate buffer at $\mathrm{pH} 8(0 \cdot 15 \mathrm{M}$ sodium chloride; $0 \cdot 015 \mathrm{M}$ sodium citrate). Denatured DNA (dDNA) was prepared by immersing a sample of this stock solution in a boiling water bath for $15 \mathrm{~min}$ before plunging it into an ice bath. DNA solutions were stored at $4^{\circ} \mathrm{C}$ and made up fresh each week. Before use they were diluted in citrate buffer to $20 \mathrm{mg} / \mathrm{l}$.

Wells were coated with $100 \mu$ l of nDNA or dDNA overnight at room temperature. After washing with $\mathbf{0 . 8 5} \%$ sodium chloride plates were incubated in the presence of $1 \%$ bovine serum albumin (Fraction $\mathrm{V}$, Miles Laboratories) in PBS. Plasma samples which had been diluted 1 in 20 with PBS containing $0.05 \%$ Tween 20 were then introduced and incubation carried out. The plates were next incubated in the presence of goat antihuman immunoglobulin conjugated to alkaline phosphatase (Litton Bionetics, USA). The conjugates, which were specific for IgG or IgM, were diluted appropriately in PBS/Tween 20. After a standard and a sodium chloride wash $\mathbf{1 0 0}$ $\mu \mathrm{l}$ of $p$-nitrophenyl phosphate (Sigma) at $1 \mathrm{~g} / \mathrm{l}$ in diethanolamine buffer was introduced. ${ }^{7}$ After incubation optical density was determined at $405 \mathrm{~nm}$ by Multiskan (Flow Laboratories).

The mean of three replicate determinations on each plasma was corrected for background obtained in the absence of DNA on the plate and was: expressed as a percentage of the corresponding value for the laboratory standard (ELISA units EU). This standard, present in each assay run, was क्ष partially purified immunoglobulin preparation from pooled SLE plasma.

All plasma samples were tested at a dilution of in 20. Experiments with SLE plasma in the anti- nDNA systems showed an approximate straight-line $\overrightarrow{0}$ relationship between optical density and log plasmadilution from 1 in 8 to 1 in 128. More dilute samples can be used (e.g., 1 in 400) but longer incubation iญ̂ required in the presence of the substrate.

IN H I B ITION OF ELISA

a
+
$+\infty$
0
0

Samples of a SLE plasma pool, diluted 1 in 10 in PBS/Tween 20, were mixed with an equal volume of DNA solution in the same buffer. The final DNAconcentration varied from $10^{-4}$ to $100 \mathrm{mg} / \mathrm{l}$. After $D$ incubation for $1 \mathrm{~h}$ at $37^{\circ} \mathrm{C}$ the mixtures (six응 replicates) were assayed for anti-DNA antibodies $\stackrel{\rho}{\oplus}$ The value obtained for the SLE pool incubated in $\overrightarrow{0}$ buffer alone was used to calculate the percentage्s inhibition of antibody activity by added DNA.

Plates were coated with nDNA and dDNA as described above, and these same preparations were used for inhibition. Also used in the inhibition was an Escherichia coli plasmid (pAT153 containing के $1.9 \mathrm{~kb}$ BamH1 fragment of human $\beta$-globin) re은 ferred to as nDNA-P. This highly purified prepara을 tion of $\mathrm{nDNA}$ was in circular form- $-90 \%$ supercoiP and $10 \%$ relaxed-and contained no single-stranded regions as determined by agarose gel elec:trophoresis.

FARR A S SAY

Plasma samples were tested for DNA-binding activity by the Farr technique in the clinical labora tory of the Department of Immunology, St Mary's Hospital Medical School. ${ }^{8}$ Purified $E$. coli nDNA labelled with ${ }^{14} \mathrm{C}$ was supplied by Amersham Inter을. national.

STATISTICAL ANALYSIS

Whereas control subjects were tested by ELISA fow antibodies to DNA only once, some SLE patientS were bled twice (four patients) or three times (two)o Results for each bleed are included in the figures $\overline{\mathbb{D}}$ but only the data for first bleeds were used in ${ }^{+}$ statistical analyses. Intervals between bleedingș varied between one and five months, and generally little change in antibody level was observed.

Log-transformed values of ELISA units wer@ used in comparing mean antibody levels in differento groups by Student's $t$ test. Correlation coefficient\$ 


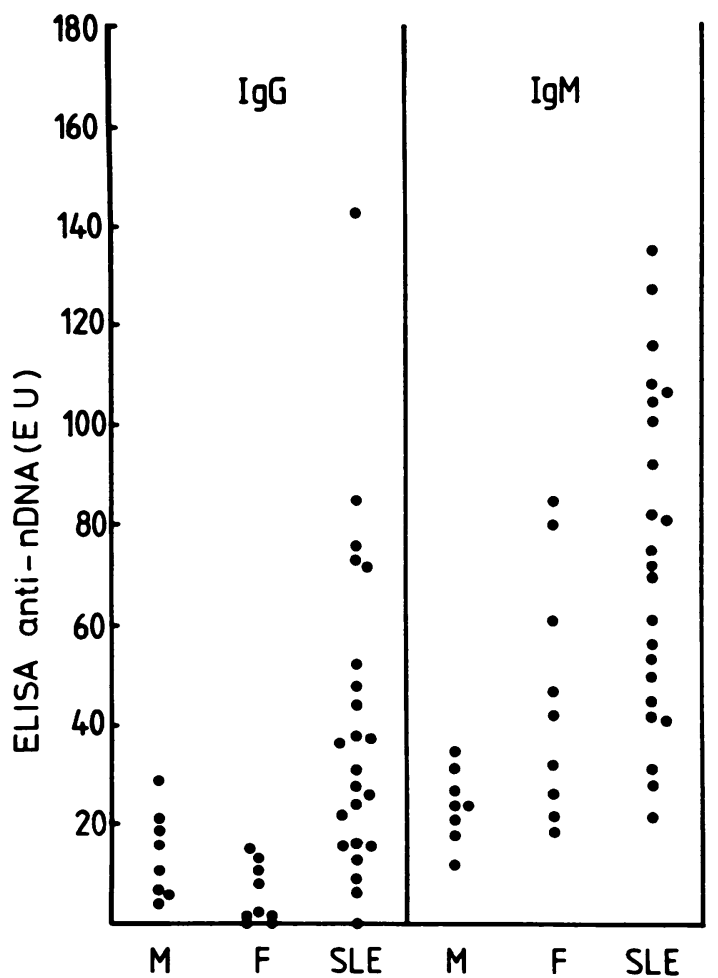

Fig. 1 IgG and IgM antibodies to $n D N A$ in SLE patients, normal females $(F)$, and normal males $(M)$.

(r) were similarly calculated on log-transformed data.

\section{Results}

ANTIBODIES TO DNA DETERMINED BY ELISA Plasma samples from normal males, normal females, and SLE patients were assayed for IgG and IgM antibodies to nDNA in the ELISA system (Fig. 1). The values obtained for normal donors were low, particularly with regard to IgG. Nevertheless, the mean value for IgG antibody was found to be less in the female group than in the males, and this was reversed for IgM ( $p<0.05$ in each case). In most of the patients IgG antibody was raised well above the level seen in the control (female) group, but for IgM considerable overlap between the groups was observed. Significant correlations were not obtained between IgG and IgM antibody levels in any of the three groups $(r=+0.46$ (SLE); +0.57 (female); +0.02 (male)).

The samples assayed for antibody to nDNA were also tested for anti-dDNA (Fig. 2). Similar results were obtained for the normal donors except that the mean value for the male group was now lower than that for the females in both tests (IgG, $\mathrm{p}<0.05$; IgM, $p>0 \cdot 05$ ). Similar results were also obtained in the comparison of patients with normal females. Again there were no significant correlations between IgG and IgM antibodies $(\mathrm{r}=-\mathbf{0} \cdot 12$ (SLE); +0.30 (female); -0.06 (male)).

In the SLE group there were significant correlations between the levels of anti-nDNA and antidDNA (IgG, $r=+0.83, p<0.001 ; \operatorname{IgM}, r=+0.55$, $\mathrm{p}<0.05)$. For the females this was the case only with IgM (IgG, $r=+0.26$; IgM, $r=+0.79, p<0.02)$; no correlations were seen in the males $(\mathrm{IgG}, \mathrm{r}=-0 \cdot 46$; IgM, $r=-0.01)$.

COMPARISON OF ELISA WITH FARR ASSAY The SLE and normal female plasmas were assayed for antibody to nDNA by the Farr test (Fig. 3). Plasmas showing binding over $30 \%$ are regarded as positive in our diagnostic laboratory and on this basis, while all the controls were negative, only six

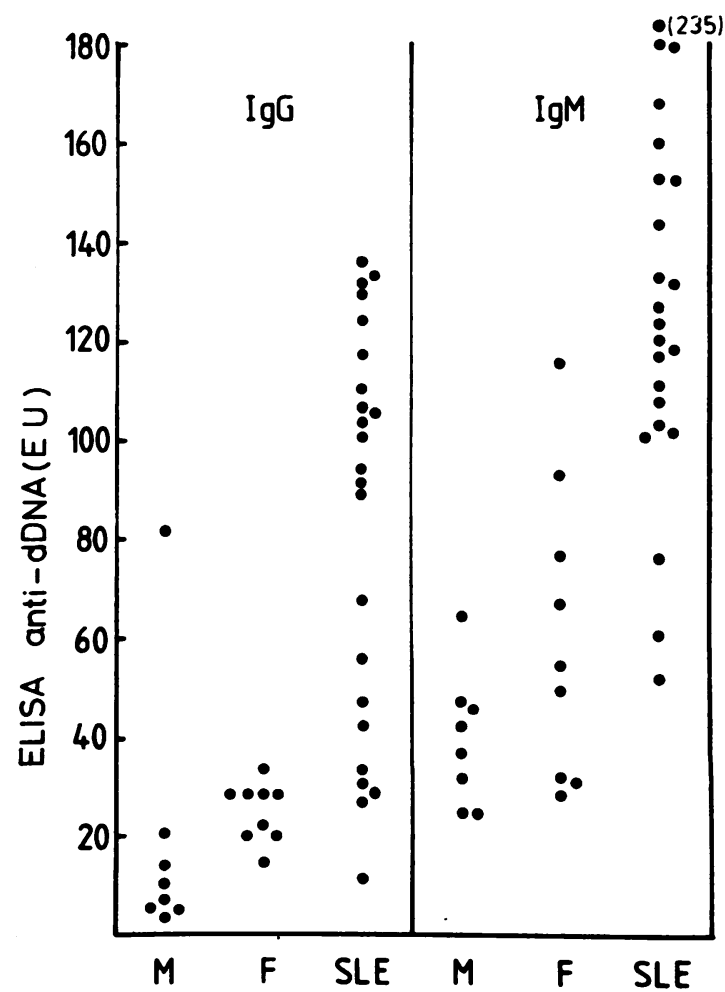

Fig. 2 IgG and IgM antibodies to dDNA in SLE patients, normal females $(F)$, and normal males $(M)$. 
of the 13 patients gave positive samples on at least one occasion over this period of experimentation. Taking from Fig. 1 provisional upper limits of normal of $20 \mathrm{EU}$ (IgG) and 90 (IgM) the corresponding figures were respectively 10 and seven out of 13. Thus ELISA for IgG anti-nDNA was better than Farr in discriminating between patients and controls.

The Farr results in SLE correlated strongly with the ELISA for IgG anti-nDNA $(r=+0 \cdot 81, \mathrm{p}<0.001)$ (Fig. 3). All eight plasmas positive by Farr were also positive by ELISA; there were another eight plasmas positive only by ELISA and another seven negative in both tests.

By contrast there was no correlation in the SLE group between Farr and the IgM ELISA $(r=+0 \cdot 09)$ (Fig. 4). Only one out of eight samples positive in IgM ELISA was also positive by Farr. Clearly IgM antibody to nDNA was not showing up strongly in the Farr test.

There was no correlation between Farr and ELISA in the normal females (IgG, $\mathrm{r}=-0 \cdot 18$; IgM, $\mathrm{r}=+0 \cdot 21)$.

SPECIFICITY OF ANTIBODIES TO DNA The specificity of the antibodies detected in the ELISA assays for anti-nDNA and anti-dDNA was

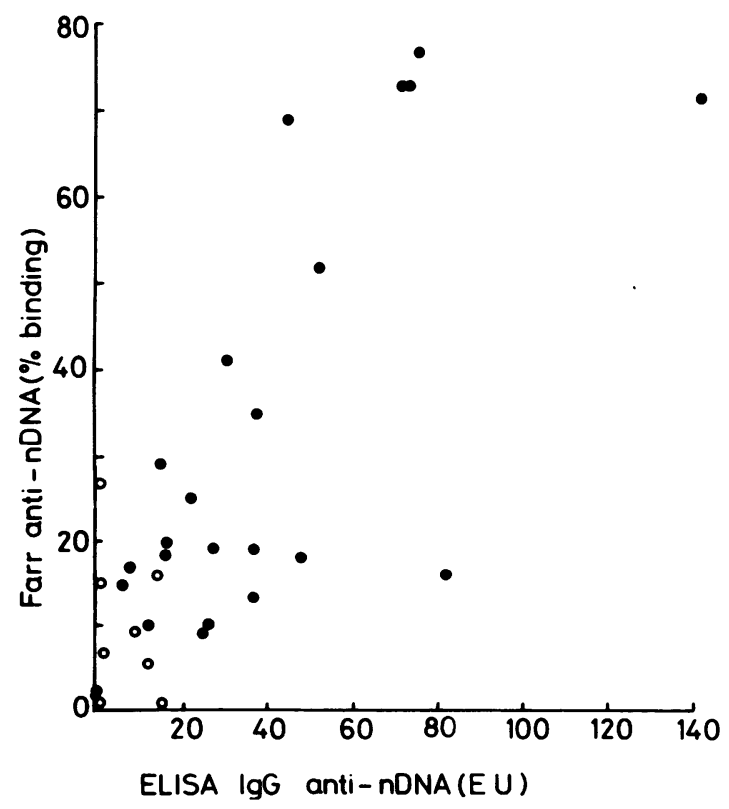

Fig. 3 Relationship between anti-nDNA levels determined by the Farr test and by ELISA for IgG antibodies. SLE patients (O); normal females (O).

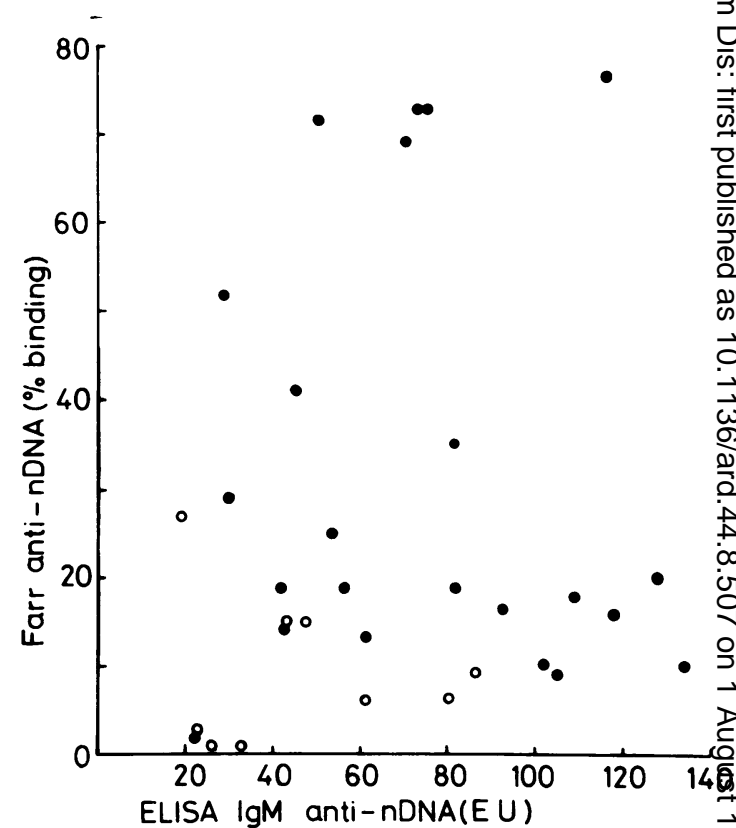

Fig. 4 Relationships between anti-nDNA levels determined by the Farr test and by ELISA for IgM antibodies. SLE patients (O); normal females (O).

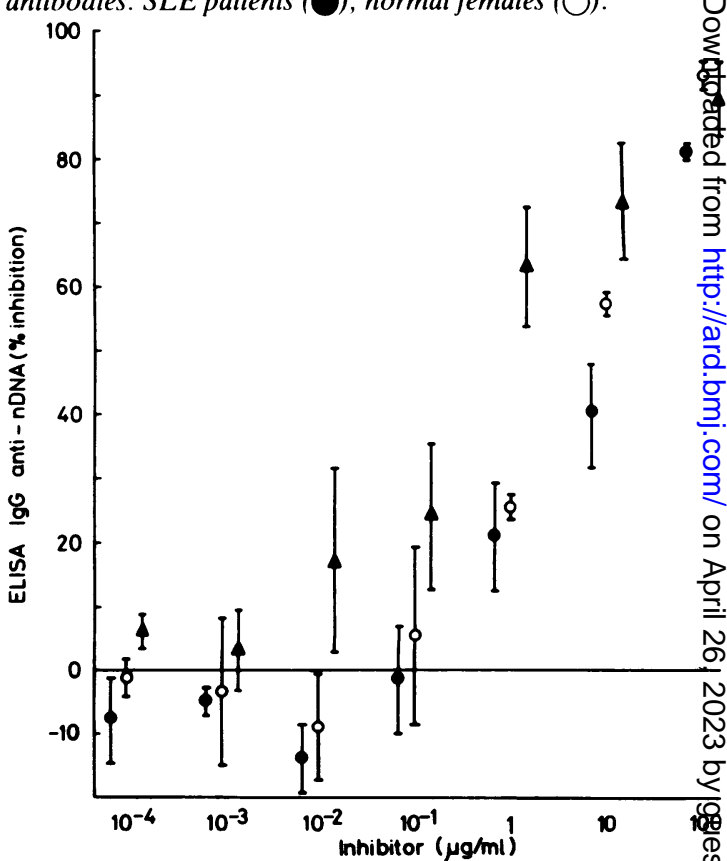

Fig. 5 Inhibition of ELISA for IgG antibodies to NDNA in the presence of our standard preparations of $n D N A(O)$ and $d D N A(\Delta)$ and of plasmid DNA (nDNA-P) (O). Three experiments were carried out but one did not include the highest level of inhibitor $(100 \mu \mathrm{g} / \mathrm{ml})$. Percentage inhibition is given as mean $\pm S E M$. (SI conversion : $\mu g / m l=m g / l)$. 


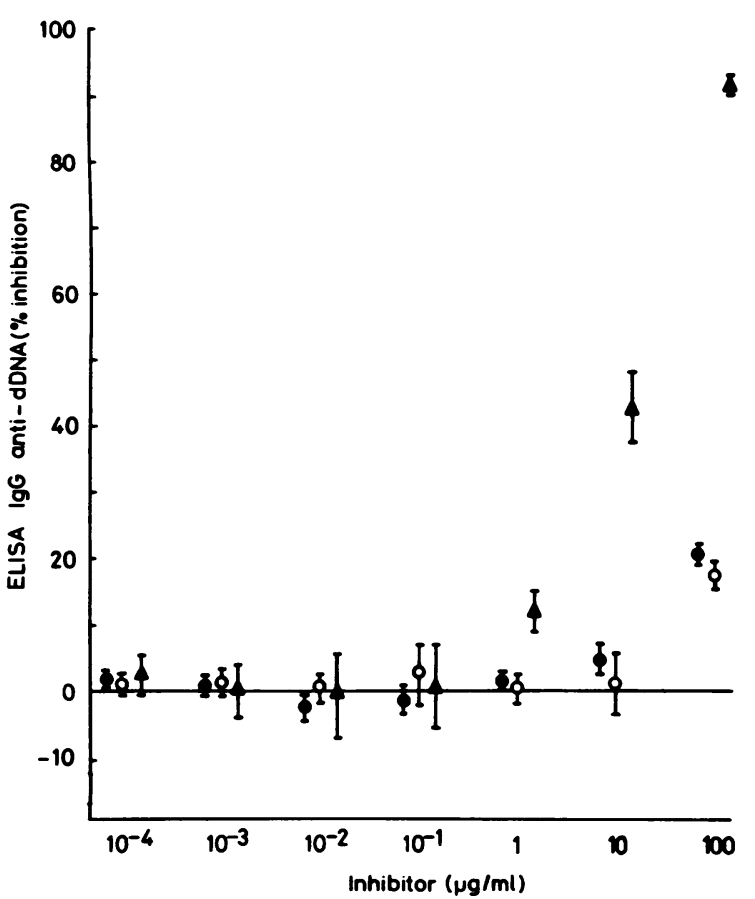

Fig. 6 Inhibition of ELISA for IgG antibodies to dDNA. Other details as Fig. 5.

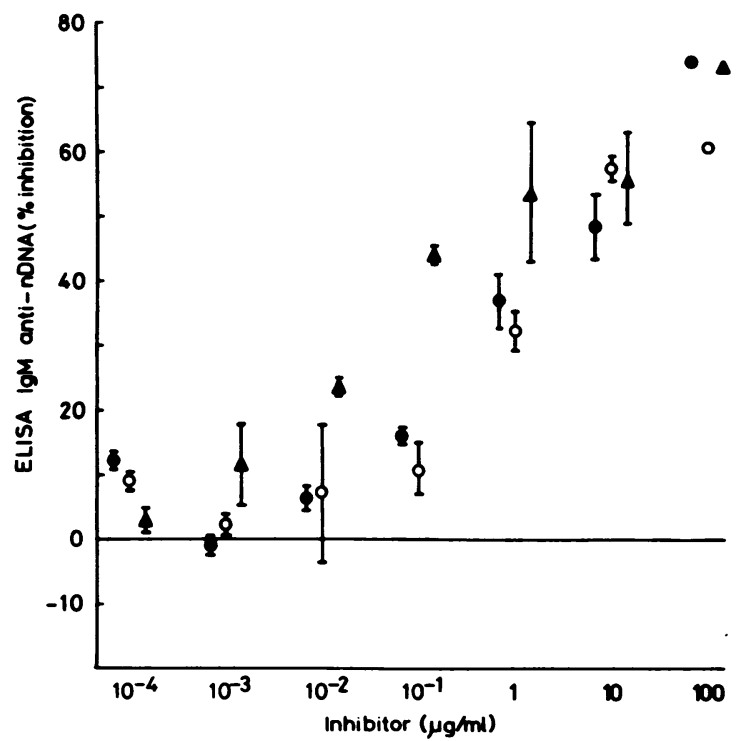

Fig. 7 Inhibition of ELISA for IgM antibodies to NDNA in the presence of our standard preparations of $n D N A(O)$ and DDNA ( 1 ) and of plasmid DNA (nDNA-P) (O). Two experiments were carried out but one did not include the highest level of inhibitor $(100 \mu \mathrm{g} / \mathrm{ml})$. Percentage inhibition is given as mean $\pm S E M$. (SI conversion: $\mu \mathrm{g} / \mathrm{ml}=\mathrm{mg} / \mathrm{l}$ ).

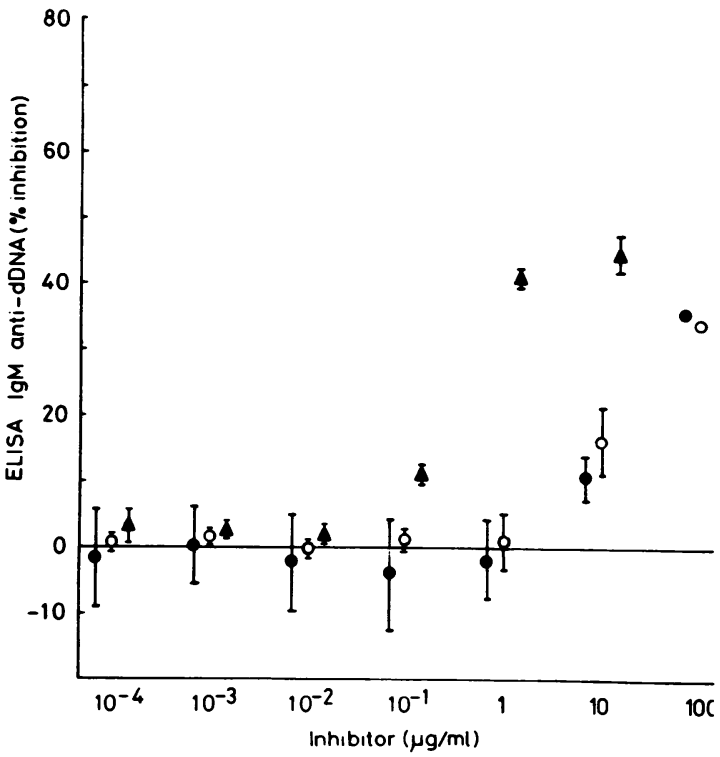

Fig. 8 Inhibition of ELISA for IgM antibodies to dDNA. Other details as Fig. 7.

investigated in inhibition experiments. Samples from a pool of SLE plasmas were incubated with a range of concentrations of our standard preparations of nDNA and dDNA and a highly purified native plasmid DNA (nDNA-P) before the assays were performed. In both types of assay for IgG antibodies dDNA gave almost complete inhibition by a concentration of $100 \mathrm{mg} / \mathrm{l}$ (Figs 5 and 6 ). In the assay for anti-nDNA this performance was matched by both nDNA and nDNA-P, but in that for anti-dDNA little inhibitory effect was seen with the native forms. dDNA at lower concentrations appeared to be a more potent inhibitor than the native forms in the assay for anti-nDNA.

Similar results to these were obtained in the assays for IgM anti-nDNA and anti-dDNA (Figs 7 and 8). Inhibitory effects were seen at lower concentrations of DNA but, in the 'native' assay, the inhibition curves were flatter. In comparison with the IgG assay the native forms in high concentration appeared more effective at inhibition of anti-dDNA antibodies (Fig. 8).

\section{Discussion}

The ELISA for IgG antibodies to nDNA gave results in SLE patients which correlated strongly with those obtained by the standard Farr test. Indeed it was more successful than Farr in differentiating between patients and normal donors. 
Although detailed analysis of this data according to disease activity is not appropriate, it was noted that only one out of seven samples negative by ELISA ( $<20 \mathrm{EU})$ came from a patient considered clinically active, whereas only one of five registering over 60 units was from an 'inactive' donor.

In marked contrast the ELISA results for IgM antibodies to nDNA showed no correlation with Farr, and it must be concluded that the latter test did not provide a satisfactory assay for such antibodies. The high salt concentration used for precipitation of bound antigen in the Farr test may give rise to preferential dissociation of IgM because of the generally lower affinity of its binding sites and the apparent tendency of IgG to engage in highly stable bivalent bonding to single DNA molecules. ${ }^{4}$ Other groups have shown similar strong correlation between ELISA and Farr for IgG anti-nDNA; for IgM significant correlations were obtained but these were notably weaker than for IgG. ${ }^{9} 10$

The lack of correlation between IgM anti-DNA and Farr observed in the present system emphasises the possibility of obtaining useful information by simultaneous measurement of both IgG and IgM antibodies. For example, a predominance of IgM may be indicative of less active disease. ${ }^{11}$

Levels of anti-nDNA in SLE patients determined by ELISA correlated with those of anti-dDNA, particularly strongly in the case of $\mathrm{IgG}$. Do these correlations reflect genuine correspondence between levels of different antibodies or is there a trivial explanation, namely that the same antibodies are registering in both systems? The results of the inhibition tests show that different antibodies are indeed being assayed.

Both native and denatured preparations of DNA were effective inhibitors in the assay of IgG and IgM antibodies to nDNA. However, since the plasmid (nDNA-P) is known to contain no single-stranded regions, most of the antibodies registering in this assay must have been capable of reacting with native structures. The ability of dDNA to inhibit the 'native' assay could result from the presence of intrastrand base pairing in our dDNA, ${ }^{12}$ but such an explanation is not supported by preliminary observations with a single-stranded preparation (RAF16-a derivative of bacteriophage M13 singlestranded DNA) as inhibitor, which is unable to form stable double-helical regions. It seems more likely to be due, therefore, to cross reactions between the deoxyribose-phosphate backbone on double- and single-stranded molecules. The enhanced potency at lower concentrations of dDNA as compared with nDNA could result from the greater flexibility of the single-stranded molecule which increases the oppor- tunity for the highly avid bivalent bonding to singlex? molecules. ${ }^{4} 13$

In the assay for antibodies to dDNA, on the other hand, dDNA was a much more effective inhibitor? than were the preparations of nDNA. What then had become of the antibodies which had been shown in the 'native' assay to bind to both nDNA ank dDNA? The conclusion must be drawn that suche antibodies form a minor group in comparison withthose directed against determinants which are specific for the single strand, presumably the base-related determinants, which are not exposed in nDNA. Antibodies to nucleosides are known to occur in SLE, though their quantitative relationship to othere anti-DNA antibodies is not clear. ${ }^{14}$ In mouse SLE $\stackrel{+\infty}{\circ}$ however, they do appear to form the bulk of their antibodies against dDNA. ${ }^{15}$ Such a swamping effect may be less marked for IgM, which was relatively? more sensitive to inhibition by nDNA.

Specificity of ELISA for antibodies to DNA has also been investigated by other groups, though theye did not include a study of IgM antibodies or employ? an inhibitor preparation comparable in definition to $\overrightarrow{0}$ nDNA-P. ${ }^{16-18}$ The results for IgG or combineof classes were in general agreement with those pre sented here, but considerable variation in the behaviour of individual sera was observed. For example, some sera showed greater potency of nDNA than dDNA in the inhibition of the 'native' assay. ${ }^{18}$

Moderately high levels of IgM anti-DNA were found in some normal females, and this may be related to the higher levels of total IgM seen in females as compared with males. ${ }^{19}$ The differences observed between normal males and females for IgG are difficult to interpret, since the low ELISA values obtained may well represent non-specific interaction between immunoglobulin and DNA. In仓̊ the Farr assay binding up to $30 \%$ is seen with normal samples, and this must be of high affinity, though not necessarily involving immunoglobulin. ${ }^{3}$ Our $>$ ELISA results for normal females did not appear toㅡ. correlate with Farr, and the whole question off normal levels of anti-DNA antibodies requires further investigation.

In seems then that the ELISA system described ${ }^{\omega}$ fulfils the requirements for an assay of antibodies to DNA set out at the beginning of this paper. Furthere tests (data not shown) have provided no evidence of interference in the assay by plasma rheumatoid factors (see also ref. 10). Particular advantages of $\frac{0}{0}$ the system are that specificity. is obtained without

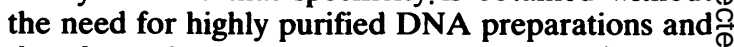
that the antigen is applied directly to the microtitre $\varrho$ plate without a precoating step. ${ }^{20}$ The ELISA? 
system is now being tested further to assess its value in both the diagnosis and monitoring of SLE and other diseases.

We thank Susan Aylen for her technical assistance, Michael Gevaux for his help in drawing the figures, and Dr L A Aarden and Dr B D Stollar for most helpful discussions. The work was supported by a grant from the Arthritis and Rheumatism Council.

\section{References}

1 Lewkonia $\mathbf{R}$ M. Barth $\mathrm{P}$ T. Hale G M. Hughes G R V. Specificity and clinical relevance of antibodies to doublestranded DNA. Ann Rheum Dis 1977; 36 (suppl 1): 114-8.

2 Talal N, Pillarisetty $R$. Filter radioimmunoassay for antibodies to DNA and RNA. Ann Rheum Dis 1977; 36 (suppl 1): 82-6.

3 Aarden L A, Smeenk R. Measurements of antibodies specific for DNA. In: Lefkovits I. Pernis B. eds. Immunological methods. New York: Academic Press, 1981: II: 75-82.

4 Aarden L A. Measurement of anti-DNA antibodies. Ann Rheum Dis 1977: 36 (suppl 1): 91-5.

5 Koffler D, Carr R. Agnello V. Thoburn R, Kunkel H G. Antibodies to polynucleotides in human sera: antigenic specificity and relation to disease. J Exp Med 1971; 134: 294-312.

6 Tan E M, Cohen A S, Fries J F, et at. The 1982 revised criteria for the classification of systemic lupus erythematosus. Arthritis Rheum 1982; 25: 1271-7.

7 Voller A. Bidwell D E. Bartlett A. The enzyme linked immunosorbent assay (ELISA). Guernsey: Dynatech Europe. 1979.

8 Cohen S A. Hughes G R V. Noel G L. Christian C L. Character of anti-DNA antibodies in systemic lupus erythematosus. Clin Exp Immunol 1971; 8: 551-61.

9 Labrousse H, Tron F, Avrameas S. Bach J F. Direct evaluation of class-specific anti-DNA antibodies by an immunoenzymatic technique. J Clin Lab Immunol 1980; 3: 191-5.

10 Karsh J. Halbert S P. Anken M. Klima E. Steinberg A D. Anti-DNA, anti-deoxyribonucleoprotein and rheumatoid factor measured by ELISA in patients with systemic lupus erythematosus, Sjögren's syndrome and rheumatoid arthritis. Int Arch Allergy Appl Immunol 1982; 68: 60-9.

11 Pennebaker J B, Gilliam J N. Ziff M. Immunoglobulin classes of DNA binding activity in serum and skin in systemic lupus erythematosus. J Clin Invest 1977; 60: 1331-8.

12 Stollar B D. Papalian M. Secondary structure in denatured DNA is responsible for its reaction with antinative DNA antibodies of systemic lupus erythematosus sera. J Clin Invest 1980: 66: $210-9$.

13 Aarden L, Smeenk R. Immunochemical properties of antibodies to DNA and their influence on detection methods. In: Kalden J R. Feltkamp T E W. eds. Antibodies to nuclear antigens. Amsterdam: Excerpta Medica, 1982: 23-30.

14 Stollar B D. Nucleic acid antigens. In: Sela M, ed. The antigens. New York: Academic Press. 1973; 1: 1-85.

15 Munns T W. Liszewski M K. Hahn B H. Antibody-nucleic acid complexes. Conformational and base specificities associated with spontaneously occurring poly- and monoclonal anti-DNA antibodies from autoimmune mice. Biochemistry 1984: 23: 2964-70.

16 Gripenberg M, Linder E. Kurki P. Engvall E. A solid phase enzyme-linked immunosorbent assay (ELISA) for the demonstration of antibodies against denatured. single-stranded DNA in patient sera. Scand J Immunol 1978: 7: 151-7.

17 Klotz J L. Minami R M. Teplitz R L. An enzyme-linked immunosorbent assay for antibodies to native and denatured DNA. J Immunol Methods 1979; 29: 155-65.

18 Eaton R B. Schnneider G. Schur P H. Enzyme immunoassay for antibodies to native DNA. Specificity and quality of antibodies. Arthritis Rheum 1983: 26: 52-62.

19 Rhodes K. Scott A. Markham R L. Monk-Jones M E. Immunological sex differences. A study of patients with rheumatoid arthritis, their relatives, and controls. Ann Rheum Dis 1969: 28: 104-20.

20 Rubin R L, Joslin F G. Tan E M. An improved ELISA for anti-native DNA by elimination of interference by anti-histone antibodies. J Immunol Methods 1983: 63: 359-66. 


\section{Book review}

Clinical Trials in the Rheumatic Diseases. By D. Rosenbloom, P Brooks, N Bellamy, W Buchanan. Pp. 386. £39·50. Praeger: New York. 1985.

The authors set out to review such clinical trials as have been conducted in the rheumatic diseases. Individual chapters are devoted to trials in osteoarthritis, rheumatoid arthritis, juvenile arthritis, seronegative arthritides, crystal arthritis, systemic lupus erythematosus, and low back pain. In addition, there is a useful preliminary chapter on methodological considerations in clinical trials and a final chapter which includes a proposal for a system by which the design, execution, and analysis of trials may be coded so as to improve reporting and interpretation of trials.

Each chapter includes discussion of methodological problems relevant to the disease and recommendations on methods to be used in future studies. Clinical trials are discussed in general terms in the text, while specific comments on methodology and results are included in tables. This format does not make for particularly easy reading, especially since the abbreviations used in the tables are not always self evident. Despite the length of the book, discussion of individual drugs is often brief; for instance trials of penicillamine in rheumatoid arthritis are dealt with in less than two pages of text and three pages of tables. The authors state that they have made no attempt to provide guidelines for prescribing since they recognise that formalised trials are not the only source of information used by clinicians in therapeutic decision making. Indeed while reading this book one is repeatedly struck by the fact that common beliefs regarding therapy in rheumatic disorders, such as the relative efficacy of different nonsteroidal anti-inflammatory drugs, are clearly based on factors other than the results of clinical trials.

This book is an invaluable source of references to clinical trials reported up to 1983, and the associated comments on methodology should be read by anyone planning to undertake a trial in the rheumatic diseases.

Consultant Rheumatologist,

R C BUTLER

Robert Jones and Agnes Hunt

Orthopaedic Hospital,

Oswestry

Correction: Evaluation of an ELISA system for determination of class-specific antibodies to native and denatured DNA in man

In the paper by G M Halliday, M R Salaman, M H Seifert, K J Johnson, and A D B Malcolm (Ann Rheum Dis 1985; 44: 507-13) we regret that Fig. 8 was incomplete. The figure and explanatory text are reproduced below.

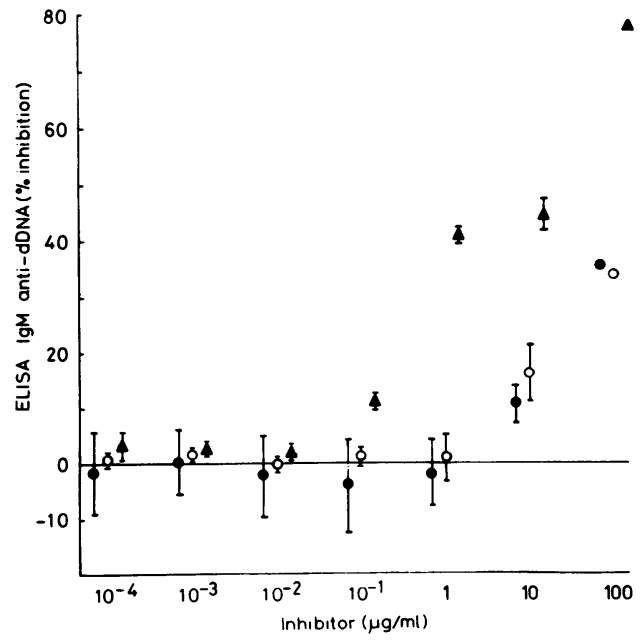

Fig. 8 Inhibition of ELISA for IgM antibodies to denatured DNA (dDNA) in the presence of our standard preparations of native DNA ( $n D N A)(0)$ and DDNA ( $\mathbf{\Delta})$ and of plasmid DNA ( $D D N A-P)$ (O). Two experiments were carried out but one did not include the highest level of inhibitor $(100 \mu \mathrm{g} / \mathrm{ml})$. Percentage inhibition is given as mean \pm SEM. (SI conversion: $\mu \mathrm{g} / \mathrm{ml}=\mathrm{mg} / \mathrm{l})$.

The source of antibodies was pooled plasma from patients with systemic lupus erythematosus. The figure was previously printed without the triangle point at $100 \mu \mathrm{g} / \mathrm{ml}$ which demonstrates a high level of inhibition by dDNA. The native preparations were less potent inhibitors at this and lower concentrations, and these results may be compared with those obtained in the inhibition of ELISA assays for IgM antibodies to nDNA and for IgG anti-DNA antibodies (Figs 5-7). 